\title{
Spontaneous rupture of giant hydatid cyst of lung into left bronchus: Preoperative diagnosis and treatment
}

\author{
Sagar Eknath Rathi ${ }^{1{ }^{*}}$, Sandya $\mathbf{P}^{1}$, Atul Jivan Bonde ${ }^{1}$, Nanda Kishor Kumar $\mathbf{V}^{1}$, Krishna Kumar KV ${ }^{2}$ and Krishna $\mathbf{M}^{3}$ \\ ${ }^{1}$ Department of Pediatrics, Krishna Institute of Medical Sciences, Minister Road, Secunderabad-500003, Telangana, India \\ ${ }^{2}$ Department of Cardiovascular Surgery, Krishna Institute of Medical Sciences, Minister Road, Secunderabad-500003, Telangana, India \\ ${ }^{3}$ Department of Anaesthesia, Krishna Institute of Medical Sciences, Minister Road, Secunderabad-500003, Telangana, India
}

\begin{abstract}
Introduction: Hydatid disease is a parasitic infestation caused by Echinococcus granulosus in which human is accidental intermediate host. Lung is the most common site involved in children unlike adults, where liver is involved.

Case report: 13-year-old girl who was asymptomatic, was found to have reduced air entry on left side during health checkup. Chest radiography (CXR) was suggestive of radio-opaque lesion obscuring left cardiac border and left dome of diaphragm. CT chest report was suggestive of intrapulmonary hydatid cyst. However, few hours after admission, she developed anaphylactic reaction which was managed successfully with adrenaline and steroids. Repeat chest readiograph was suggestive of decreased opacity, air fluid level noticed on dependent part of left lung. Rupture of the cyst was suspected. She underwent left thoracotomy and evacuation of hydatid cyst was done. Intra-operative findings were suggestive of broken endocyst, thoracic cavity filled with fluid with multiple bronchial openings.
\end{abstract}

Conclusion: Hydatid cyst despite of its thick covering layers, undergoes spontaneous rupture occasionally. Anaphylactic shock due to rupture of cyst is a life threatening complication.

Keywords: hydatid cyst; rupture; anaphylactic reaction; enucleation of cyst

*Corresponding author: Dr. Sagar Eknath Rathi, DNB Resident, Department of Pediatrics, Krishna Institute of Medical Sciences, Minister Road, Secunderabad-500003, Telangana, India. Mobile: 9908183708; Email: sagarrathi07@gmail.com

Received 15 December 2017; Revised 22 February 2017; Accepted 01 March 2017; Published 10 March 2017

Citation: Rathi SE, Sandya P, Bonde AJ, Kumar VNK, Kumar KVK, Krishna M. Spontaneous rupture of giant hydatid cyst of lung into left bronchus: Preoperative diagnosis and treatment. J Med Sci Res. 2017; 5(2):72-76. DOI: http://dx.doi.org/10.17727/ JMSR.2017/5-14

Copyright: (C) 2017 Rathi SE et al. Published by KIMS Foundation and Research Center. This is an open-access article distributed under the terms of the Creative Commons Attribution License, which permits unrestricted use, distribution, and reproduction in any medium, provided the original author and source are credited.

\section{Introduction}

Hydatid disease is a parasitic infestation caused by larval stage of the dog tapeworm Echinococcus. Lung hydatid cysts measuring more than $10 \mathrm{~cm}$ in the largest diameter are defined as giant hydatid cyst. Giant pulmonary hydatid cysts can be located elsewhere in the chest but in literature they were located most commonly in the right lower lobe [1]. We are reporting rare a case of spontaneous rupture of pulmonary hydatid cyst involving left lower lobe, which was successfully treated with surgery.

\section{Case report}

A 13-year-old girl was brought by her father with 
complaints of cough and cold since last two days with no history of fever nor breathing difficulty along with chest pain. She had no history of contact with TB patient. She came from lower socioeconomic class, with poor housing and sanitation. She was completely immunized according to EPI schedule. Father was operated for some liver mass five years back (no documentation available) and he is butcher by occupation.

Physical examination revealed decreased movement of left side of chest with deviation of trachea to right with stony dull note on percussion with decreased air entry in left infra-mammary, axillary, infraaxillary, interscapular and infra-scapular areas.

Chest radiograph showed a well defined round radiopaque lesion of $16.4 \times 9.4 \mathrm{~cm}$ obscuring left cardiac border and left dome of diaphragm (Figure 1). CT scan showed well-defined cystic lesion measuring $17.1 \times 10 \mathrm{~cm}$ in size in posterior basal segment of left lower lobe - intrapulmonary hydatid cyst (Figure 2a,b).

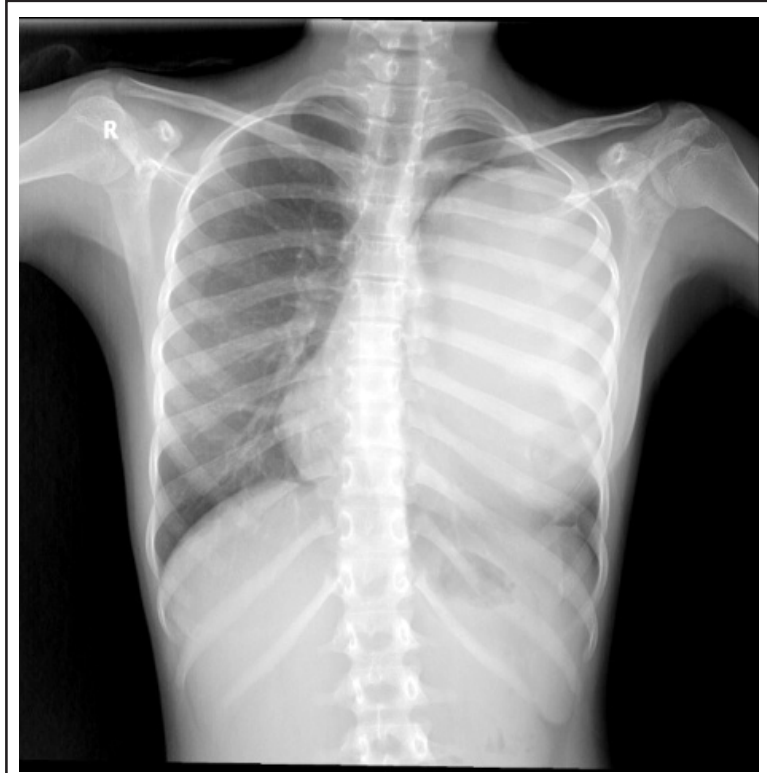

Figure 1: Chest radiograph on admission shows a welldefined radio-opaque shadow in left hemithorax.

She was admitted and started with Tab. Albendazole, supportive management and planed for surgery. After $12 \mathrm{~h}$ of admission, she had one episode of coughing of white material which was salty in taste followed by breathing difficulty and desaturation up to $75 \%$ with high grade fever (104.2 F) associated

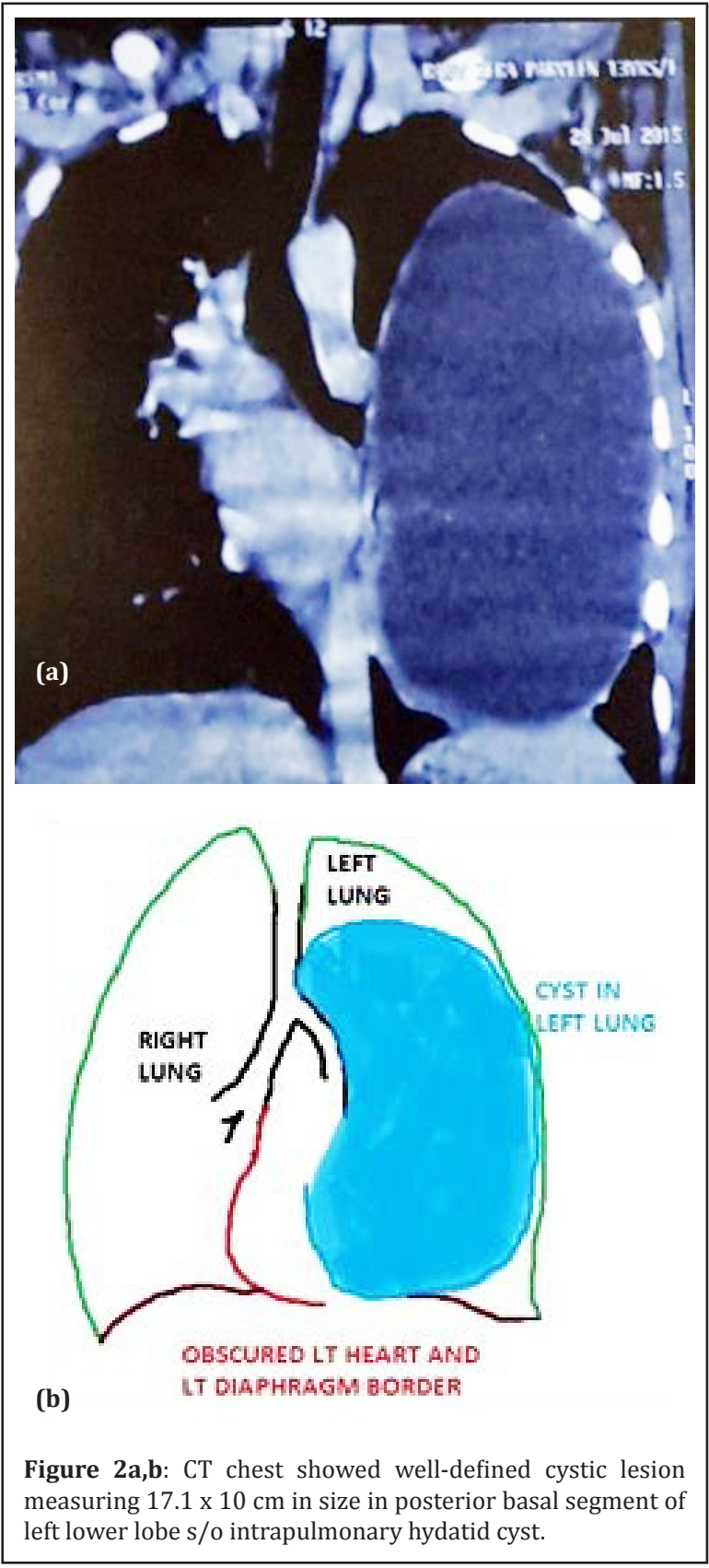

with chills and rigors suggestive of anaphylactic reaction - rupture of cyst. Repeat chest radiograph was suggestive of decreased opacity, air-fluid level noticed on dependent part of left lung probably due to rupture of cyst (Figure 3). She was shifted to PICU and was started on IV steroids (Hydrocortisone 2 $\mathrm{mg} / \mathrm{kg} /$ dose $6^{\text {th }}$ hourly), IV adrenaline and oxygen support, following which symptoms subsided. Cardiothoracic surgeon opinion was sought who advised thoracotomy and enucleation of cyst. Left thoracotomy was done. Intra-operative finding is suggestive of $10 \times 6 \mathrm{~cm}$ cyst extending from fissure 
downwards. The endocyst is broken, thoracic cavity filled with fluid, with multiple bronchial openings. Bronchial openings were sutured and Enucleation of cyst was done (Figures 4 \& 5). She was closely monitored for vitals and extubated on $3^{\text {rd }}$ postoperative day. Postoperatively she had smooth recovery. Postoperative chest radiograph shows improvement (Figure 6). She was discharged on $7^{\text {th }}$ postoperative day with an advice to continue Tab. Albendazole $200 \mathrm{mg}$ twice a day for next one month. On follow up, she was asymptomatic and her chest radiograph showed complete separation of remaining left lung (Figure 7).

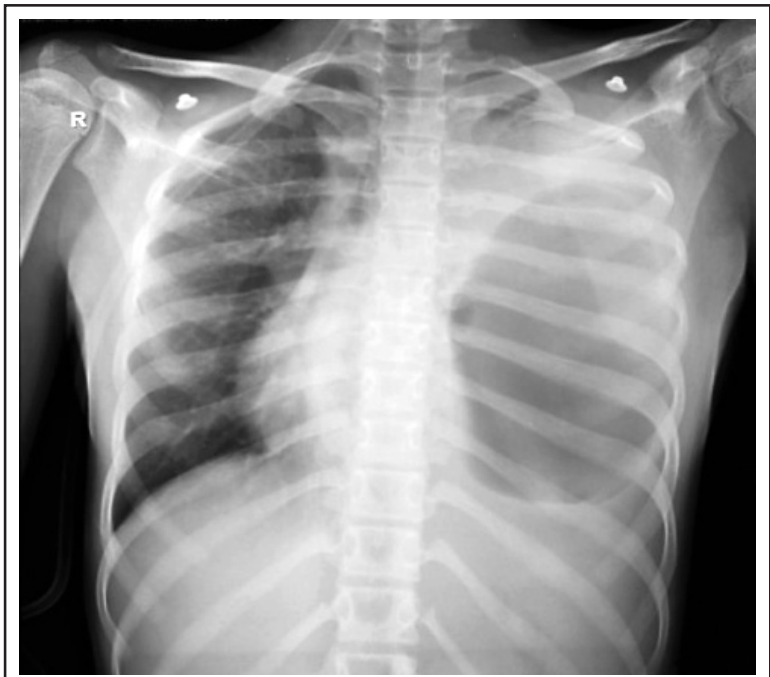

Figure 3: After $12 \mathrm{~h}$ of admission, chest radiograph showed disappearance of radio-opaque shadow with presence of air fluid level.

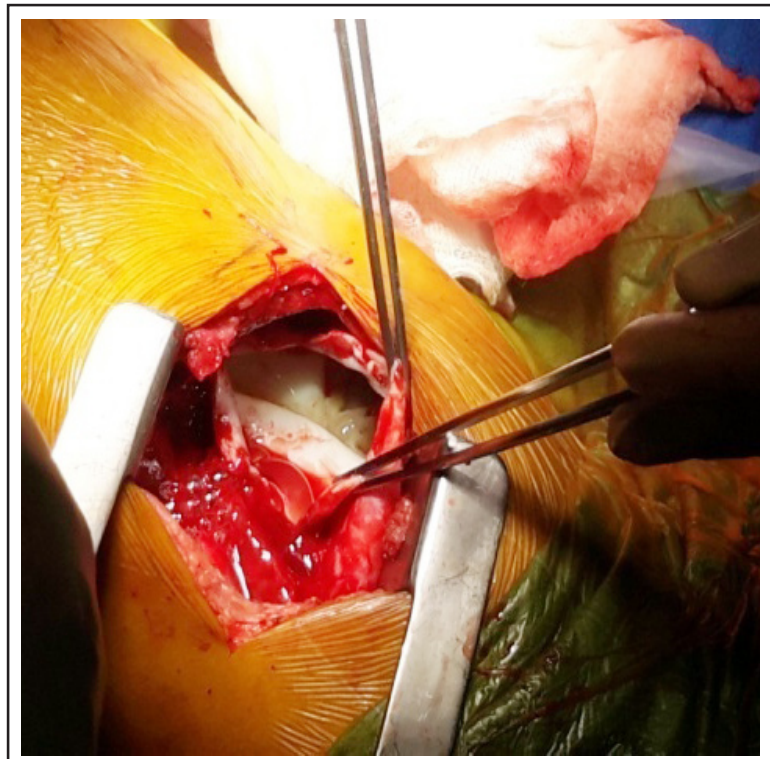

Figure 4: Intra-operative photo suggestive of ruptured hydatid cyst of lung.

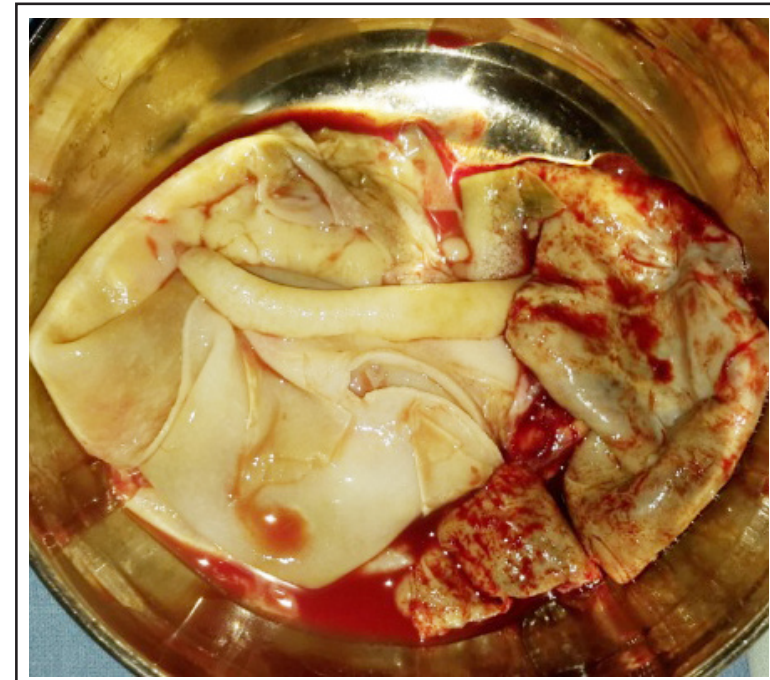

Figure 5: Image shows specimen of hydatid cyst.

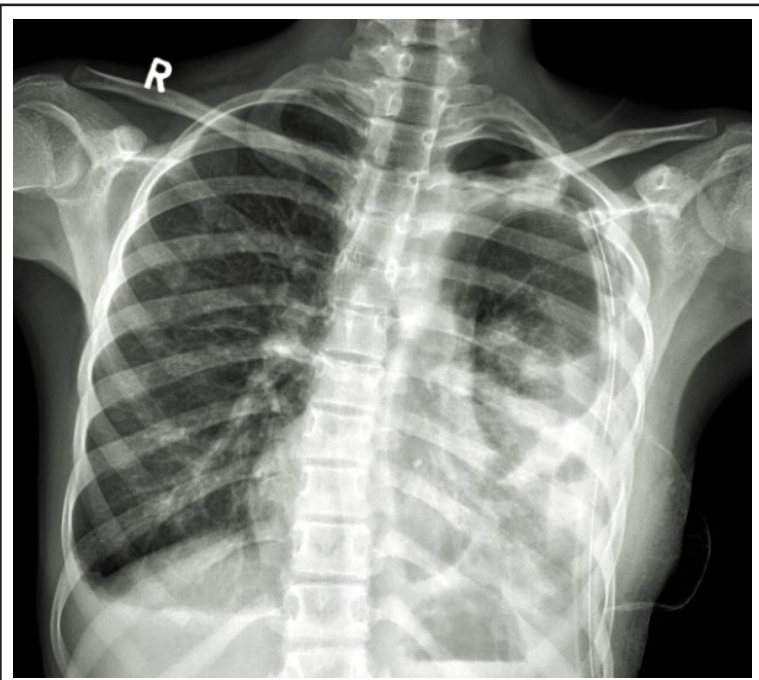

Figure 6: Postoperative chest radiograph shows underlying collapse/ consolidation of left lower lobe with ICD in situ.

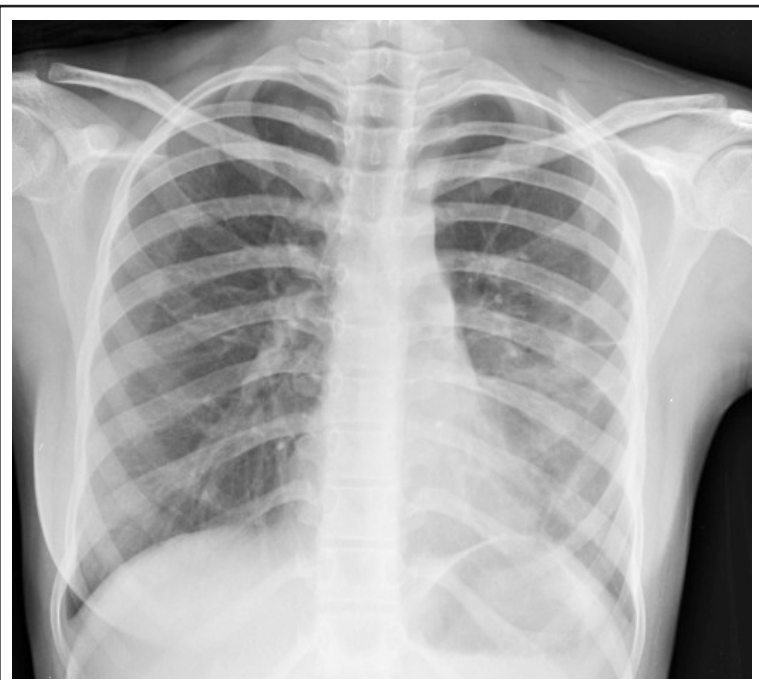

Figure 7: After completion of treatment chest radiograph shows complete absence of radio-opaque shadow. 


\section{Discussion}

Hydatid disease caused by larval stage of Echinococcus granulosus. The definitive host is the dog, while the intermediate hosts are cattle and sheep. Human is accidental host. Transmission of the disease to humans by ingestion of eggs which are present in the contaminated water and food. There are several domestic animals that may be involved, as an intermediate host of echinococcosis transmission such as sheep, pigs, goats and cattle [2]. If the cyst ruptures, patient may develop allergic symptoms and anaphylaxis, transbronchial spread to other lobes, pleural hydatidosis and pleural effusion [3]. However in our case, it present as anaphylactic reaction, with rupture of cyst in bronchial tree.

The primary infection with Echinococcus granulosus is believed to occur during childhood. As hydatid cysts grow slowly, clinical symptoms do not usually arise until several years after infestation, before being diagnosed radiologically on radiography chest. Most often it is an incidental finding. In adults, disease primarily involves the liver (50-70\%), however the majority of children present with lung involvement (64\%) [4]. Hydatid cysts in the lungs are multiple in $30 \%$ of cases with bilaterality seen in $20 \%$ and the preferential location being the lower lobes in $60 \%$ of the cases. Calcification is a rare phenomenon [5].

The diagnosis of pulmonary hydatid disease rests on clinical, radiological, and serological examinations [6]. The most important diagnostic tool is imaging. An unruptured cyst appears as a spherical, well-circumscribed, homogenous opacity. Its size may vary from a few centimeters to $20 \mathrm{~cm}$. A small amount of air may enter the zone between the pericyst and ectocyst layers due to increased intrathoracic pressure (eg., coughing, trauma). In a radiograph, it looks like an air shadow at the top of the cyst and is known as a crescent sign, moon sign, or meniscus sign [7]. This is probably the first sign before rupture of the cyst. When air freely enters the cyst and displaces the cystic fluid after complete rupture of the laminated membrane, an air-fluid level is formed, as in our case.

Although rare, fatal anaphylaxis can occur which may be life threatening. Rupture of the cyst is reported to occur in $34 \%$ to $64 \%$ of the patients [2]. Rupture may occur spontaneously or during coughing, sneezing, or because of a blunt chest trauma. Iatrogenic rupture during needle aspiration may also occur. A giant cyst is expected to rupture more easily. The rupture may be contained within the pericyst or drained into a bronchus. Massive drainage of cyst fluid into the bronchus may cause severe anaphylaxis, aspiration, suffocation, or even death [8]. In the event of rupture of the cyst, the cyst fluid, membranes, and scolices may be expectorated [9]. The cyst may even rupture into the pleural cavity.

The principal mode of treatment in pulmonary hydatid disease is surgery. For pulmonary hydatid cyst, surgery is a safe and effective way of treatment, along with perioperative albendazole therapy [10]. The current treatment is complete excision with maximum preservation of lung tissue. Surgical intervention should consist of closing all bronchial openings after the membrane of the cyst has been removed [11].

Toavoid recurrence of hydatidcyst, medical treatment with albendazole or mebendazole is used, together with surgical treatment. It is given pre-operatively to prevent the possible consequences of rupture of the cysts during surgery, and postoperatively as adjuvant therapy, for cysts that may have ruptured during surgery [12]. Albendazole is the preferred medication because it displays better cyst penetration than other benzimidazoles [13]. The WHO-IWGEguidelines recommend administering $10-15 \mathrm{mg} / \mathrm{kg}$ daily in two doses for 1 month.

\section{Conclusion}

Lung preserving surgery should be preferred in pulmonary hydatid cyst, to get satisfactory results. Early identification and surgical removal of cyst will improve the symptoms. Anaphylactic shock due to rupture of cyst is a life threatening complication, which requires emergency treatment. Treatment with anti-helminthic drugs in the peri-operative phase will prevent recurrence of the disease.

\section{Acknowledgements}

The Department of Radiology \& Imageology, Krishna Institute of Medical Sciences (KIMS), Secunderabad500003, Telangana, India.

\section{Conflicts of interest}

Authors declare no conflicts of interest. 


\section{References}

[1] Arroud M, Afifi MA, Ghazi KE, Nejjari C, Bouabdallah Y. Lung hydatic cysts in children: Comparison study between giant and non-giant cysts. Pediatr Surg Int. 2009; 25(1):37-40.

[2] Topçu S, Kurul IC, Taştepe I, Bozkurt D, Gülhan E, et al. Surgical treatment of pulmonary hydatid cysts in children. J Thorac Cardiovasc Surg. 2000; 120(6):1097-101.

[3] Ozdemir A, Bozdemir SE, Akbiyik D, Daar G, Korkut S, et al. Anaphylaxis due to ruptured pulmonary hydatid cyst in a 13-year-old boy. Asia Pac Allergy. 2015; 5(2):128-131.

[4] Cangir AK, Sahin E, Enon S, Kavukcu S, Akay H, et al. Surgical treatment of pulmonary hydatid cysts in children. J Pediatr Surg. 2001; 36(6):917-920.

[5] Zahirifard S, Karam MB, Kaynama K, Farzanegan R, Tahbaz MO, et al. Imaging in 100 patients of thoracic hydatid disease including unusual imaging appearances. Iran J Radiol. 2006; 3(2):91-97.

[6] Craig PS, McManus DP, Lightowlers MW, Chabalgoity JA, Garcia HH, et al. Prevention and control of cystic echinococcosis. Lancet Infect Dis. 2007; 7(6):385-394.

[7] Barret NR, Thomas D. Pulmonary hydatid disease. Br J Surg 1952; 40(161):222-224.

[8] Boots RJ. "Near drowning" due to hydatid disease. Anaesth Intensive Care. 1998; 26(6):680-681.

[9] Pedrosa I, Saíz A, Arrazola J, Ferreirós J, Pedrosa CS. Hydatid disease: Radiologic and pathologic features and complications. Radiographics. 2000; 20(3):795-817.

[10] Ghoshal AG, Sarkar S, Saha K, Sarkar U, Kundu S, et al. Hydatid lung disease: An analysis of five years cumulative data from Kolkata. J Assoc Physicians India. 2012; 60(7):12-16.

[11] Turna A, Yilmaz MA, Haciibrahimoğlu G, Kutlu CA, Bedirhan MA. Surgical treatment of pulmonary hydatid cysts: Is capitonnage necessary? Ann Thorac Surg. 2002; 74(1):191195.

[12] Keshmiri M, Baharvahdat H, Fattahi SH, Davachi B, Dabiri $\mathrm{RH}$, et al. A placebo controlled study of albendazole in the treatment of pulmonary echinococcosis. Eur Respir J. 1999; 14(3):503-507.

[13] Ben Brahim M, Nouri A, Ksia A, El Ezzi O, Krichene I, et al. Management of multiple echinococcosis in childhood with albendazole and surgery. J Pediatr Surg. 2008; 43(11):20242030. 